
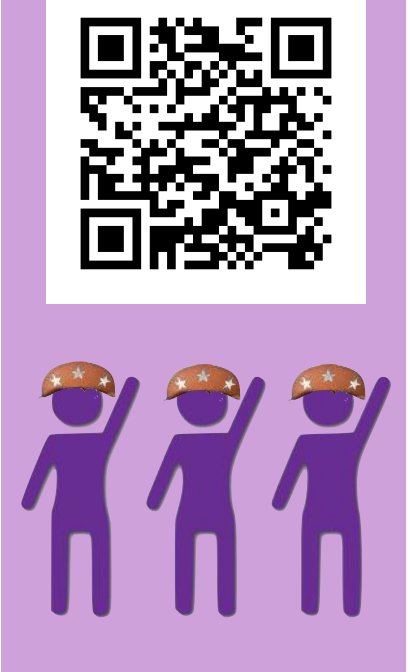

\title{
O FEMINISMO NEGRO NA LITERATURA DE CORDEL DE JARID ARRAES E EM CONTOS DE MIRIAM ALVES
}

Flávia Andrea Rodrigues BENFATTI, Universidade Federal de Uberlândia Gláucia Mendes da SILVA, Universidade Federal de Uberlândia

Este artigo objetiva refletir sobre o feminismo negro no Brasil, trazendo algumas vozes teóricas que traçam um percurso desse movimento. Para tanto, duas escritoras contemporâneas farão coro à essas vozes. Verificaremos de que forma o canto libertário de Jarid Arraes ecoa em seus versos cordelianos bem como sob qual perspectiva a narrativa áspera de Miriam Alves aponta-nos caminhos para outros olhares sobre racismo, violência e sexismo. Dessa forma, tanto os versos de Arraes quanto a prosa de Alves são como uma "cusparada na cara" dos preconceitos e estereótipos criados contra a mulher negra.

PALAVRAS-Chave: Feminismo negro; Literatura de Cordel; Jarid Arraes; Prosa; Miriam Alves. 


\section{Introdução: Breve História dos Movimentos Feministas Branco e Negro}

O movimento feminista tem suas origens na Europa e nos Estados Unidos no século XIX, organizado por mulheres brancas de classe média e alta que buscavam basicamente uma igualdade de direitos equiparadas aos direitos que os homens da mesma cor e classe social gozavam: educação, liberdade de escolha matrimonial e exercício das diversas profissões de forma remunerada. Historicamente, o movimento feminista europeu e estadunidense é categorizado por três ondas, a partir do século XIX, a saber: a primeira onda, teve como pauta principal o direito à educação e à uma igualdade nas relações dentro do casamento. É nessa onda também que as mulheres se engajam na luta pelo voto e pela abolição da escravidão nos Estados Unidos da América, movidas pelos ideais Iluministas.

Já a segunda onda teve como mote o questionamento do que é ser mulher, colocando em pauta as místicas atribuídas ao sexo feminino, iniciando assim as discussões sobre gênero. É a partir da década de 1960 que surgem esses pensamentos, que tendem a radicalizar o movimento feminista, atribuindo a especificidade de lutas com pautas exclusivas das e pelas mulheres. A terceira onda é datada da década de 1990, e tem como característica principal o olhar pela diversidade, compreendendo que o movimento feminista não poderia continuar uniforme perante as diversas realidades das mulheres ao redor do mundo, com demandas específicas inerentes a classe social, raça, nacionalidade, sexualidade, etc. Muito embora as mulheres brancas tivessem pensado sobre a condição de escravização da mulher negra, na prática, elas acabavam não as incluindo em suas discussões e muito menos, as lésbicas e as travestis.

No Brasil, o movimento feminista branco ergueu sua primeira bandeira no início do século XIX, reivindicando o direito à escolarização, que até o ano de 1827 era reservado aos homens. As poucas mulheres que tinham o privilégio de receber educação domiciliar iniciaram um enfrentamento para que todas as mulheres pudessem ter o direito à educação, a aprender a ler e a escrever. Nesse cenário, surge o nome de Nísia Floresta (1810 - 1885), primeira mulher brasileira a publicar textos reivindicando o direito das mulheres. Em 1832 Nísia Floresta publicou o livro Direitos das mulheres e injustiça dos homens, no qual exigia respeito à intelectualidade feminina e à capacidade de exercer profissões 
igualmente aos homens, dentre outras reivindicações inerentes às causas feministas da época.

Nísia Floresta foi desbravadora da luta feminista no Brasil, pois buscou implantar aqui as ideias que absorvia do pensamento feminista europeu. Para Constância Lima Duarte 3 (2019, pág. 29) "ela (Nísia) empreende uma espécie de antropofagia libertária: assimila as concepções estrangeiras e devolve um produto pessoal, em que cada palavra é vivida e os conceitos surgem extraídos da própria experiência”. Dessa forma, Nísia Floresta incentivou várias outras mulheres brasileiras a escreverem e a publicarem seus livros no século XIX, enfrentando uma sociedade bastante machista e repressora. Os periódicos também foram instrumentos significativos de divulgação dos textos escritos pelas mulheres, como o "Jornal das Senhoras" e "O Belo Sexo", jornais que eram mantidos pelas intelectuais da alta classe do Rio de Janeiro, que publicavam textos visando a conscientização das mulheres acerca da busca pelos seus direitos.

Apesar da importância desse período inicial do movimento feminista no Brasil, é notável a sua limitação a um circuito específico de mulheres escolarizadas e com condições financeiras, pois o direito à escolarização para todas ainda dava seus primeiros passos. Duarte (2019) questiona o pouco conhecimento que se tem a respeito da história do feminismo no Brasil, afirmando que a divulgação do movimento se limita à década de 1930, com a luta pelo voto, ou a bandeiras específicas, como a questão do aborto, por exemplo, deixando de lado todo o restante da história. Para ela:

[...] o feminismo, a meu ver, deveria ser compreendido em um sentido mais amplo, como todo gesto ou ação que resulte em protesto contra a opressão e a discriminação da mulher, ou que exija a ampliação de seus direitos civis e políticos, por iniciativa individual ou de grupo. Somente então será possível valorizar os momentos iniciais dessa luta - contra os preconceitos mais primários e arraigados - e considerar aquelas mulheres que se expuseram à incompreensão e à crítica, nossas primeiras e legítimas feministas (DUARTE, 2019, p. 26).

Seguindo essa premissa de divulgação da história do feminismo no Brasil, Duarte (2019) categoriza o movimento feminista brasileiro em quatro momentos, de forma didática, imprimindo a cada um características da luta e nomes de mulheres que fizeram a diferença, seja por meio da luta política ou por meio da divulgação das ideias em artigos de periódicos e em obras literárias. 
Resumidamente, os momentos descritos por Duarte (2019) são: o primeiro, iniciado com a luta de Nísia Floresta pela abertura de escolas para mulheres, no início do século XIX, já mencionado acima. O segundo momento, por volta de 1870, marcado pela expansão de jornais e revistas feministas, caracterizando-se por um cunho mais jornalístico estendido a outras regiões brasileiras fora do eixo Rio de Janeiro e São Paulo. A reivindicação pelo 4 direito ao voto deu o primeiro passo nesta época, com a peça O Voto Feminino, de Josefina Álvares, exibida em 1878. O terceiro momento, no século XX, é marcado pela conquista do direito ao voto pelas mulheres, no governo de Getúlio Vargas, bem como pela ascensão de escritoras romancistas, como Raquel de Queiroz, e a realização da "Primeira Exposição do Livro Feminino", em 1946 e 1947, reunindo centenas de escritoras no Rio de Janeiro e em São Paulo.

Finalmente o quarto momento, já nos anos de 1970, no qual a luta das mulheres brasileiras foi "contra a ditadura militar e a censura, pela redemocratização do país, pela anistia e por melhores condições de vida" (DUARTE, 2019, pág. 42) sem abandonar os ideários de autonomia sobre o próprio corpo e de liberdade sexual. Entretanto, na pauta desses momentos do feminismo branco, não houve inserção das mulheres negras.

De acordo com Núbia Moreira, em um programa da série "O que querem as mulheres?” com curadoria de Margareth Rago, apresentado no YouTube em 20 de novembro de 2016 e Djamila Ribeiro, em artigo para a revista Cult online, publicado em nove de junho de 2017, o movimento feminista negro no Brasil ganha força na década de 1980, embora nos anos 1970 as mulheres negras já organizavam suas plataformas de ações políticas, nas palavras de Moreira. Ribeiro cita que a década de 1970 é o marco inicial da visibilidade dos ideais de luta das mulheres negras nos Estados Unidos, até então desfocadas dos movimentos das mulheres brancas, principalmente pelas vozes das intelectuais afro-americanas e que, obviamente, vieram a influenciar mais tarde o feminismo brasileiro, dando espaço para que o feminismo negro se caracterizasse como uma forte vertente do pensamento feminista no Brasil a partir dos anos 1980.

Segundo Ribeiro (citando b. hooks), ao feminismo negro acadêmico, junta-se a militância, uma importante conexão entre teoria e prática. Além disso, fazem parte da luta das mulheres negras não apenas o sexismo (igual para negras e brancas) mas ainda o racismo e o classismo (pontuado por diversas feministas negras norte-americanas e brasileiras, tais como as já mencionadas neste artigo, b hooks, Constância Lima 
Duarte, Djamila Ribeiro, dentre outras). Ou seja, as mulheres negras ainda tem mais desafios a vencer do que a mulheres brancas.

Djamila Ribeiro (citando Nubia Moreira) relata que acontece, em 1985, o " $3^{\circ}$ Encontro Feminista Latino-Americano". Nesse encontro, há uma participação coletiva de mulheres negras com pauta política e, a partir de então, a construção de outros coletivos de 5 mulheres negras em nível estadual e nacional a fim de dar visibilidade aos ideais das lutas feministas negras. Outro ponto marcado por Ribeiro é o fato de que:

[...] não existem ondas específicas em relação ao feminismo negro porque as mulheres negras foram silenciadas no interior do movimento, já que suas lutas não eram consideradas feministas mesmo quando produziam e criavam, historicamente, formas de resistência.

Diante do exposto, não podemos negar que o movimento de mulheres negras vem de longa data, sendo todas as mobilizações de extrema importância para a força do movimento hoje, tanto nos ativismos como na escrita literária ou no ambiente acadêmico. As mulheres negras vêm, cada vez mais, ocupando seus espaços de direito, embora a luta seja bem mais árdua para elas. Além disso, o enfrentamento das disparidades sociais, políticas e econômicas tem sido essencial para o fortalecimento da luta antirracista no Brasil, desencadeando debates em diversos setores tais como no mercado de trabalho, na saúde, na educação, nos meios de comunicação, etc., nos quais a desigualdade era (e ainda é) gritante entre negros e brancos. Nesse sentido, a contribuição do feminismo negro tem sido fundamental para a conscientização e luta antirracista, antisexista e anticlassista nas últimas décadas no Brasil.

O Brasil é o quinto maior país no ranking populacional do mundo, sendo a maioria desta população composta por mulheres. De acordo com dados da PNAD (Pesquisa Nacional por Amostra de Domicílios) de 2018, a porcentagem de mulheres é de $51,7 \%$ e de homens é de $48,3 \%$, em uma quantidade de 208,5 milhões de habitantes. Números significativos que revelam também um dado negativo: dessa maioria de mulheres, uma enorme parcela vive em condições de violência de gênero, em números alarmantes. O Brasil ocupa a quinta posição mundial no que diz respeito aos índices de países que mais praticam a violência contra as mulheres. Racionalmente soa contraditório que a população que ocupa a maioria em número é vítima constante de massacres dos mais variados, praticados pela minoria de homens. Da porcentagem de 51,7\% de mulheres no Brasil, a maioria são mulheres negras (as que se consideram pardas entrariam aqui também, no entanto, não temos uma porcentagem precisa dessas 
mulheres no Brasil). Todas sofrem com a violência, entretanto, a mulher negra é ainda mais vulnerável.

Os desdobramentos dos números acima elencados são os mais diversos: as mulheres brasileiras, além de vítimas de constante violência, são minoria nas lideranças dos diversos poderes, chegando a ser ínfima a porcentagem feminina que ocupa cargos de chefia ou de autoridade no executivo, legislativo e judiciário. A desigualdade de oportunidades no mundo do trabalho também é imensa e a desigualdade salarial entre mulheres e homens exercendo 6 as mesmas profissões é latente, mais ainda quando se trata da mulher negra, sem mencionar o número de mulheres integrantes de grupos específicos, como as indígenas, as quilombolas, as trans mulheres e as travestis, por exemplo, que ainda vivem submetidas a uma total dominação e violência masculina mascarada por questões morais, religiosas ou culturais. Perante essas e outras questões, abordar o feminismo, principalmente o feminismo negro no Brasil, é uma questão de necessidade, uma obrigação de nós, mulheres brancas, para com o saldo da dívida histórica que temos com as negras/os em nosso país. Há de se sublinhar que tanto as mulheres brancas quanto as negras, em todo o mundo, vêm pleiteando seus lugares de fala ao longo de alguns séculos, no entanto, o lugar "reservado" para as mulheres negras está muito aquém de suas necessidades.

\section{O Pensamento Feminista Negro e a Literatura Brasileira}

No ano de 1851, uma mulher negra norte-americana chamada Sojouner Truth proferiu um discurso em uma Convenção pelos Direitos das Mulheres em Akron, que acontecia em Ohio, nos Estados Unidos. Esse discurso marcou a história do feminismo com foco nas mulheres negras, pois, ao ser proferido por uma ex escrava, diante de homens e mulheres brancas que levantavam bandeiras de igualdade de direitos entre si e não enxergavam as diferenças que limitavam a vida das mulheres negras, chocou os que estavam ali presentes e marcou as futuras gerações. Truth mostrou a limitação daquela luta, que segregava as vidas negras de uma forma tão sub-humana que nenhuma daquelas reivindicações as contemplava, simplesmente pelo fato de que o primeiro direito que as mulheres negras necessitavam era o de serem vistas como seres humanos, como mulheres. Apesar de o discurso ter passado por várias traduções ao 
longo dos séculos, a tradução que move os estudos brasileiros impacta pelo célebre questionamento de Truth: "não sou eu uma mulher?".

Anos depois de Truth proferir o emocionante discurso, o movimento feminista negro começa a se consolidar nos Estados Unidos, no século XX, por meio das vozes de intelectuais afro-americanas que reconhecem e lutam contra o sistema de opressão a que as mulheres negras viviam (e vivem) submetidas historicamente. Movimentos e coletivos começam então a reunir as vozes dessas mulheres que, a partir de suas experiências no trabalho, na família e no dia-a-dia, reivindicam seus espaços de fala em busca de uma resistência contra o racismo e o sexismo que as tem objetificado e oprimido desde então. 7 Patrícia Hill Collins, no artigo "Pensamento feminista negro: o poder da autodefinição", afirma que:

As ideias e ações das mulheres negras norte-americanas forçam a repensar o conceito de hegemonia, a noção de que a objetificação da mulher negra como outro é tão completa que nos tornamos participantes voluntárias em nossa própria opressão (COLLINS, 2019, pág. 273).

Ou seja, os discursos que objetificam as mulheres negras são tão poderosos que as próprias mulheres acabam, muitas vezes, por incorporálos como verdadeiros. São discursos repetitivos e de reafirmação do poder da hegemonia branca masculina, portanto, é preciso decolonizar as mentes das mulheres que se subjugam por acreditarem na própria objetificação como algo natural.

Sueli Carneiro (2019), ao refletir sobre o feminismo negro no Brasil, afirma que a experiência histórica das mulheres negras é diferenciada e que o discurso clássico sobre a opressão feminina não as reconhece em suas especificidades e efeitos que perduram há séculos. Por exemplo, segundo a autora, quando se fala da fragilidade feminina, ela questiona de que mulheres estão falando, pois as mulheres negras nunca foram frágeis, não tiveram a proteção paternalista que as brancas tiveram. As mulheres negras, contrariamente

trabalharam durante séculos como escravas nas lavouras ou nas ruas, como vendedoras, quituteiras, prostitutas...Mulheres que não entenderam nada quando as feministas disseram que as mulheres deveriam ganhar as ruas e trabalhar. Fazemos parte de um contingente de mulheres com identidade de objeto. Ontem, a serviço de frágeis sinhazinhas e de senhores de engenhos tarados (CARNEIRO, 2019, p.314). 
Dessa forma, observa-se que as mulheres negras tem uma história de opressão completamente diferente da história das mulheres brancas. As mulheres negras tem um trabalho muito mais fastidioso na tentativa de mostrar que suas experiências trouxeram outras prioridades em suas lutas e que não são as mesmas prioridades das mulheres brancas. Portanto, segundo Collins, "a questão mais abrangente de encontrar uma voz para expressar um ponto de vista coletivo e autodefinido das mulheres negras permanece o tema principal do pensamento feminista negro" (COLLINS, 2019, pág. 274).

Considerando as reflexões de Collins (2019) e Carneiro (2019), é possível sintetizar que a pauta do feminismo negro latino-americano tem como base a conscientização do peso da questão racial na vida das mulheres negras, desdobrando-se em agendas específicas como: 8 a violência racial; as questões de saúde pública, na qual se negligencia as características particulares da raça negra; as disparidades no mercado de trabalho, seletivamente branco, mascarado pela exigência da "boa aparência”; a objetificação do corpo da mulher negra, tanto para a exploração no trabalho braçal e doméstico quanto na sexualização desses corpos; a exploração do trabalho e do sexo do corpo infantil da menina negra; a vulnerabilidade das mulheres negras a agressões no ambiente de trabalho, na rua e nos meios de comunicação, dentre inúmeras outras causas que perpassam a realidade cotidiana das vidas femininas negras.

Em resumo, a luta do feminismo negro é pela dignidade dessas vidas e por justiça social. Embora o "feminismo branco e negro" ${ }^{\text {" divergem }}$ em diferentes pontos, já que as vivências das mulheres brancas e negras são diferentes, ainda assim podem haver ideais comuns, como por exemplo, a luta contra o patriarcado. Tanto as mulheres negras quanto as brancas estão de acordo de que essa luta é de todas nós (e de homens também, embora não em sua maioria) inseridos nos "Sistemas-mundo"2, para nos apropriarmos do termo de Ramón Grossfoguel.

\footnotetext{
${ }^{1}$ Estamos utilizando "feminismo branco e negro" (entre aspas) como generalizações. Na verdade, existem várias frentes feministas brancas e negras, já vivemos em contextos variados e plurais. Não pretendermos reduzir feminismo a um binarismo, mas isso seria pauta para um outro artigo. Aqui queremos apontar, de forma geral, as diferenças de lutas entre o feminismo branco e negro para que o leitor possa entender que não se pode colocar tudo dentro de uma caixinha apenas. Diante da pluralidade de contextos históricos, culturais e sociais, sabemos não haver mais espaço para reducionismos binários.

2 Para Grossfoguel, “o conceito de 'sistema-mundo' é um movimento de protesto dentro das ciências sociais eurocêntricas contra as análises que utilizam a categoria 'sociedade', entendida como equivalente ao 'Estadonação', pois o sistema mundo se refere à sociedades globais já que vivemos em temporalidades e espacialidades de 'sociedades globais', ou seja, temos muito do norte no sul, do sul no norte e assim por diante (GROSFOGUEL, 2019, p. 62).
} 
Assim, espera-se que o feminismo negro cresça cada vez mais e conquiste seus espaços de fala em contextos cada vez mais variados.

\section{A Cordelista e a Contista}

A arte desde sempre tem sido espaço de resistência e de voz às diversas causas que, de alguma forma, destoam do que preconiza o modelo patriarcal hegemônico. A literatura exerce papel fundamental de resistência, e na história do movimento feminista sempre esteve atuante, por meio das publicações das mulheres que lutam pelos seus direitos e buscam a arte como forma de expressão. Diversas obras literárias tem influenciado os pensamentos feministas ao longo dos tempos, expressando, em versos ou em prosa, as vozes das lutas das mulheres. No cenário da literatura brasileira, grandes nomes têm se destacado como representantes da luta do feminismo negro a partir das últimas décadas.

Alguns nomes importantes de escritoras negras brasileiras que abordam em suas obras literárias, em versos e prosa, as questões defendidas pelo movimento feminista negro são: Maria Firmina dos Reis, Carolina Maria de Jesus, Conceição Evaristo, Jenyffer Nascimento, Elizandra Souza, Ana Maria Gonçalves, Alzira Rufino, Geni Guimarães, Miriam Alves, Cristiane Sobral, Esmeralda Ribeiro, Djamila Ribeiro, Jarid Arraes, dentre outras. Publicações como os Cadernos Negrostem contribuido para a formação desse espaço literário dando voz às escritoras negras, que, por muito tempo, foram banidas do circuito consagrado da literatura brasileira.

Por muito tempo, quando se discutia os gêneros literários, a literatura de cordel não era incluída, tendo em vista seu caráter popular e sua origem na oralidade, com rimas e ritmos específicos que não atendem aos padrões da literatura canonizada. Atualmente há um reconhecimento desta literatura como sendo um Patrimônio Cultural Imaterial brasileiro, título obtido em 2018, e um crescente interesse acadêmico por esta forma poética tem sido notado nos últimos anos. Símbolo de resistência, a literatura de cordel por muito tempo exerceu um papel pedagógico na educação brasileira, principalmente nas regiões Norte e Nordeste do país, como instrumento de expressão das pessoas simples, da zona rural, com pouca ou nenhuma instrução formal, mas que tomavam as rimas do cordel como meio para tratar questões de diversos temas do cotidiano, de forma lúdica, em prol da divulgação do conhecimento. 
A partir da década de 1970, a literatura de cordel se expande para outras regiões brasileiras e passa a ser interesse de escritores renomados no meio literário erudito, como Ariano Suassuna, por exemplo. Atualmente a literatura de cordel é encontrada com requintes de edições, tais como as versões dos clássicos literários adaptados para o cordel, bem como versões virtuais interativas, mesclando o visual, o poético e a tecnologia, se reinventando em todas as mídias. Neste cenário, não mais se categoriza a literatura de cordel como apenas uma literatura dos folhetos simples, ilustrados com xilogravuras e vendidos nas feiras. Os suportes evoluíram, bem como a autoria - que passa do sertanejo simples, sem estudo, para os poetas e acadêmicos das grandes metrópoles brasileiras. A literatura de cordel, por todas essas evoluções, é um campo fértil para reflexões nos estudos linguísticos e literários.

É possível encontrar vários estudos acadêmicos tratando sobre a evolução da literatura de cordel e de questões específicas desta expressão artística, tais como temas, 10 linguagem, hibridez, diálogos, etc. A forma como a literatura aborda algumas temáticas da contemporaneidade também tem sido objeto de interesse acadêmico, como o estudo de Rozeane Porto Diniz , As lésbicas do cordel (2018), que analisa as representações léxicosemânticas relativas aos relacionamentos lésbicos na literatura de cordel, e o estudo de Miguel Pereira Barros, Relações de gênero na literatura de cordel (2015), que analisa as visões de mundo das relações homem e mulher no cordel. Estes dois recentes trabalhos exemplificam o interesse acadêmico e as possibilidades que esta expressão literária representa, diante das discussões atuais dos diversos movimentos de luta.

Em seu histórico a literatura de cordel tem a autoria masculina como predominância. Uma mulher cordelista era coisa rara de se encontrar. A primeira mulher que escreveu e publicou um folheto de cordel foi Maria das Neves Batista Pimentel, em 1938. No entanto, para que seu cordel pudesse ser publicado, ela o assinou com um nome masculino, Altino Alagoano, para burlar o preconceito da época. Somente a partir do ano de 1970 as mulheres começaram a ter espaço neste meio. Até então, tanto a autoria quanto as temáticas dos cordéis eram dominados pelo mundo machista, retratando a mulher como personagens submissas ao homem nas histórias. O cenário começa a mudar a partir do século XXI, e as temáticas começam a sair desse ciclo de jocosidade machista para temáticas de reflexões sobre questões sociais, como preconceito, racismo, política, como afirma Barros (2015) "a tradição 
patriarcal começou a ser questionada, especialmente, pelas novas cordelistas que ingressam no universo do cordel, e, utilizam-se do humor para criticar as relações de gênero na sociedade" (BARROS, 2015, pág. 111).

É neste cenário renovado do mundo do cordel que se encontra a poetiza e cordelista Jarid Arraes. Mulher negra, nascida em Juazeiro do Norte - CE, filha de cordelistas, Arraes vive atualmente em São Paulo, onde criou o Clube da Escrita para Mulheres. Militante das causas do feminismo negro, possui mais de sessenta títulos publicados em Cordel, com as temáticas variadas das pautas do movimento feminista negro, com destaque para a coletânea Heroínas Negras Brasileiras em 15 Cordéis, livro no qual a história de mulheres negras brasileiras que fizeram a diferença em diversas áreas é contada em versos. Estar inserida no mundo do cordel é um ato de resistência das mulheres cordelistas. Inserir temáticas raciais e de gênero é a re-existência configurada em versos.

Por sua vez, Miriam Alves, poetiza, contista, professora e ativista, escreve desde os 11 anos de idade. Na década de 1980 passa a fazer parte do coletivo Quilombhoje Literatura, responsável pela produção dos "Cadernos Negros". A autora escreve para diversas 11 antologias brasileiras. Tem participado de debates, palestras e eventos acadêmicos no Brasil e no exterior, com interesse e foco na produção feminina negra. Também já ministrou cursos e palestras fora do Brasil: Áustria, Alemanha e Estados Unidos. É uma escritora bastante versátil e polêmica sem perder de vista seu projeto literário como forma de resgatar a identidade e humanidade das pessoas socialmente subalternizadas.

\section{Re-Existência de Vozes Femininas Negras nos Cordéis de Arraes e nos Contos de Alves}

Retomando as reflexões acima traçadas sobre a importância do feminismo no Brasil, e especificamente da relevância das pautas do feminismo negro em uma sociedade na qual a maioria da população é composta por mulheres negras, ressaltamos que a literatura, como instrumento capaz de transformar e empoderar essas mulheres, é assunto relevante.

Jarid Arraes pratica essa missão de empoderar meninas e mulheres negras por meio dos cordéis, nos quais aborda as temáticas de autodefinição, autoestima e autovalorização, bandeiras defendidas pelo 
movimento feminista negro. Assim como a música, a literatura é um instrumento de voz potente nas lutas. O cordel tem a especificidade de ser bem mais acessível do que o livro, quando se trata de valor financeiro. $\mathrm{O}$ estudioso Braulio Tavares (2019) afirma que "o cordel é o livro de quem não pode comprar livro”.

Por outro lado, guardadas as devidas proporções das diferenças entre os gêneros cordel (versos) e conto (prosa), Miriam Alves, como mulher e escritora negra, também defende a negritude, por meio de sua escrita, ao escancarar os preconceitos, o racismo, a violência de gênero e raça, sem inferiorizar a imagem da mulher negra, ou pintá-la como "frágil". Pelo contrário, suas personagens femininas, embora muitas vezes de mãos atadas, demonstram força e garra ao tentar vencer ou superar traumas inculcados pela sociedade patriarcal masculina branca (às vezes Alves coloca a mulher branca também nesse patamar).

Nesse sentido, ambas as escritoras concretizam seus projetos literários por meio de um gênero, um modo específico e peculiar de tratar de assuntos que deveriam não apenas instigar as mulheres negras à agência, mas também mostrar à sociedade em geral que há um 12 movimento negro lutando para o reconhecimento das mulheres negras (ainda, socialmente falando, consideradas abaixo do homem negro em termos de civilidade, dignidade e direitos) com as mesmas vantagens e humanidade atribuídas aos brancos. Dentre todas as hierarquias criadas pelas sociedades ocidentais discriminatórias, a mulher negra é a que ainda está abaixo de todas as categorias da escala social, se for pobre, como é o caso da maioria das negras brasileiras, muito pior.

Nesse sentido, ambas as escritoras concretizam seus projetos literários por meio de um gênero, um modo específico e peculiar de tratar de assuntos que deveriam não apenas instigar as mulheres negras à agência, mas também mostrar à sociedade em geral que há um 12 movimento negro lutando para o reconhecimento das mulheres negras (ainda, socialmente falando, consideradas abaixo do homem negro em termos de civilidade, dignidade e direitos) com as mesmas vantagens e humanidade atribuídas aos brancos. Dentre todas as hierarquias criadas pelas sociedades ocidentais discriminatórias, a mulher negra é a que ainda está abaixo de todas as categorias da escala social, se for pobre, como é o caso da maioria das negras brasileiras, muito pior. 
No cordel "Corpo Escuro", Jarid Arraes conta a história de uma personagem chamada Jana que buscou um tratamento para clarear a pele, tornando-a alva e rosada. A história se passa nos anos 3000, nos quais a tecnologia já permite tal procedimento. Jana, por ser pobre, trabalha pesado para conseguir o dinheiro para pagar o procedimento, como se pode observar nos versos abaixo:

Fez trabalho de limpeza

Pra quem não tinha dinheiro

E por isso não pagava

Por um robô faxineiro

Jana era a empregada

Mais barata e dedicada

Esfregando o dia inteiro

Jana estava exausta de tanto trabalho, mas quando se olhava no espelho, sentia desgosto e amargura devido à sua pele escura. E então conseguiu realizar seu sonho de trocar de pele e cabelo. Quando se torna branca, todos a contratam, a acham linda e a chamam de princesa:
Jana agora tinha a pele Muito alva e bem rosada
O cabelo, antes crespo
Tinha dado uma alisada
E agora era amarelo
Fino como dum bruguelo
Jana estava transformada
[...] O trabalho era melhor
Logo era a contratada
Ninguém mais mudava lado
Quando vinha na calçada
Foi chamada de princesa
Confundida com francesa
Foi ficando emocionada 
A princípio, portanto, fica feliz com o resultado, mas aos poucos começa a se entristecer por sentir-se sozinha, mesmo com a pele branca e, principalmente, por sentir falta de sua identidade perdida:

Sentiu falta do cabelo

Do volume e da textura

De sua pele que brilhava

Como se fosse uma pintura

E enfim nesse momento

No final entendimento

Quis voltar a ser escura

Ainda com relação à imagem da menina/mulher negra, Arraes dedica, em um outro cordel intitulado "Quem tem Crespo é Rainha”, a tratar apenas da questão dos cabelos, no qual a autora aborda a temática do racismo exercido desde cedo sobre as meninas negras, em relação à natureza crespa dos cabelos. Nos versos há a crítica sobre a indústria padrão de beleza que induz desde muito cedo as meninas negras a não aceitarem seus cabelos crespos ou encaracolados, fazendo uso de produtos químicos alisantes e pranchas quentes para mudar a estrutura dos cabelos, deixando-os "alisados". O tema aqui é a autoaceitação física, em que Arraes incentiva as meninas e mulheres negras a se empoderarem, aceitando suas características:
O amor pelo seu crespo
É coroa pra reinar
Imponente a aparência
Negritude a ensinar
A beleza escurecida
De orgulho fortalecida
Feita para acalentar
Não há nada de errado
Em ter o cabelo crespo
Pode ser bem enrolado
Ou um black de respeito
Pois em terra de chapinha
Quem tem crespo é rainha
Com exuberante jeito

Por sua vez, Miram Alves (2011) também traz, em seu conto "Um só Gole”, uma narradora que, caminhando a esmo, chega às margens de um rio, pensa em suicídio, questiona seus medos de viver e de morrer e, 
ao longo da caminhada, olha-se no espelho, algumas vezes, e tece comentários sobre sua figura:

Arrastei-me outra vez, ao olhar-me no espelho. Fitava-me atentamente. Lembrei do coro da garotada do passado. Ouvi, num lampejo, a famosa música de carnaval: "Nega do cabelo duro, qual é o pente que te penteia?” Música que, muitas vezes, tinha dançado nos bailes do Paulistano da Glória, fantasiada de maneira a estarem sempre guardados, sob lenços coloridos, os meus cabelos enrolados. Envergonhei-me de ser o que eu era: "Maria Pretinha". Envergonheime dos cabelos das pessoas pretas que riam e pulavam numa inconsistente alegria. Insanamente, me armei de pente-de-ferroquente e, a todo vapor, tratei de amansar a rebeldia de meus cabelos. Neste momento, ouvia aquelas vozes: "Há, há, há, ela quer ser Maria, mãe de nosso Senhor". Tentando apagar o vozerio, alisava-os. Esticavaos até não mais poder. Eu sabia. Junto com os cabelos, esticava a revolta. Domava minha consciência. Domava minha tolerância. [...] Tive um acidente, um dia. Num descuido, o instrumento autotorturador escapou de minhas mãos nervosas, caindo sobre o lado esquerdo do meu rosto. Foi um acidente. Queimei violentamente a face [...] eu era triste caricatura borrada. Eu sou uma triste caricatura borrada (ALVES, 2011, p.83,84, grifos nossos).

Percebe-se que tanto em Arraes quanto em Alves, temos um doloroso questionamento das personagens negras com relação à sua imagem. Os excertos supracitados nos levam à reflexão sobre temas profundos para as mulheres negras, como a não aceitação da cor da pele e do cabelo crespo assim como a busca constante dessas mulheres por um padrão de cor, corpo e cabelo da mulher branca europeia. Esse padrão imposto por modelos europeus massacra as mulheres negras, as escraviza em uma busca inatingível por um biotipo que não as pertence. Franz Fanon, no livro Pele Negra Máscaras Brancas, ao discutir a busca da mulher de cor para se aproximar dos padrões do homem branco, afirma que "a preta se sente inferior, por isso aspira a ser admitida no mundo branco” (FANON, 2008, pág. 66).

Para Fanon, essa busca por aceitação chega a ser patológica, em diferentes graus. Ao contar a história de Jana, Jarid Arraes conta a história de uma busca desvairada por uma pele alva e rosada, fazendo a personagem se submeter a um procedimento desconhecido em nome de um padrão inatingível de identidade: é exatamente essa busca patológica discutida por Fanon que a cordelista ilustra.

A seu turno, Alves, no trecho acima, mostra uma personagem desorientada que pensa em cometer suicídio devido à uma história de 
preconceito e discriminação sofrida na escola, na infância. A narradora personagem se sente muito decepcionada, naquele momento, ao pedir ao professor de teatro para, às voltas do natal, interpretar a personagem 15 Maria. Sempre aprendera que todos eram iguais e qual não foi a decepção quando o professor e seus colegas de classe começaram a rir com intensidade e a criançada então dizia em coro: "Maria não é preta, é Nossa Senhora. Maria não é preta, é mãe de Jesus". A partir desse fato, a personagem (que não sabemos o nome) começa a questionar a própria existência, a se olhar no espelho, e a se ver como um ser diferente. Já há tempos escondia seus cabelos enrolados em turbantes em bailes de carnaval. Então, passa a sentir vergonha de ser negra e de possuir cabelos enrolados. A dor era tanta que se sentia como um rastejador e, de tanto se curvar, arrastava-se, criando calos: "Arrastava-me, não ficava mais em pé. Eu era toda calos" (p. 84). Em um misto de sentimentos de vida e morte, ainda assim, procurava saída em suas próprias reflexões, tentando apagar esse passado e agir em seu próprio benefício. No fim, conseguiu optar pela vida.

Percebe-se, nos trechos supracitados, que as autoras retratam personagens que sofrem com a discriminação, mas que lutam por aceitação, lutam pela vida e pelo resgate de suas identidades.

A teórica do feminismo negro Ângela Figueiredo (2019) faz um questionamento e ela mesma o responde:

Mas, afinal, o que é uma imagem? As imagens são representações de si construídas pela sociedade através de seus discursos que nos constituem como sujeitos. Contudo, Collins (2000) reivindica que é preciso assumir o controle da imagem, pois somente assim será possível a construção de uma autodefinição ou de uma autoimagem positiva (FIGUEIREDO, 2019, p. 211,212).

Essa "autodefinição ou autoimagem positiva" é percebida no cordel "Corpo Escuro" e no conto "Um só gole" quando as personagens em questão buscam, no final de suas histórias, renascer, superando as dificuldades na maioria das vezes esculpidas pela sociedade hegemônica branca e discriminatória. Retomando Collins (2019) acima, a mulher negra precisa lutar contra a sua objetificação criada por essa sociedade fazendo com que ela seja a opressora de si própria, sem perceber. 
No cordel "Quem Tem Cabelo Crespo é Rainha”, há um reforço da autora em reafirmar essa autoimagem positiva. Segundo Ângela Figueiredo:

Desde os anos 1960, o cabelo crespo tem sido utilizado como símbolo afirmativo da negritude, sendo instrumento de intervenção nos mais variados contextos. O cabelo crespo sempre fez parte da imagética das representações raciais, sendo imprescindível na construção de estereótipos. 16 Por esse e outros motivos é que historicamente os negros vêm sendo vitimizados no mercado da aparência e no mundo da beleza, uma esfera marcada de modo contínuo pela construção de estereótipos negativos associados aos fenótipos negros, considerados feios, principalmente nos contextos em que há fortes e significativas desigualdades étnico-raciais (FIGUEIREDO, 2019, p. 210).

Portanto, os "estereótipos negativos" citados por Figueiredo, são desterritorializados no cordel "Corpo Escuro" e no conto "Um só Gole", pois as personagens transitam de um desequilíbrio com relação à imagem negativa a elas socialmente construída, para uma condição de enfrentamento da dor e superação do desespero. O cordel referente ao crespo, tem por "dever" dissociar a imagem do fenótipo dos negros e negras, "considerados feios" nas palavras de Figueiredo, para uma retomada da dignidade e identidade negra.

Temos ainda mais três temas, interligados, abordados pela cordelista e pela contista. Trata-se de violência, estupro e assédio contra a mulher negra. No cordel "Chica Gosta é de Mulher" e nos contos "Cinco Cartas para Rael" e "Os olhos Verdes de Esmeralda" temos personagens mulheres que sofrem nas mãos da sociedade machista patriarcal hegemônica branca.

Nos versos de Arraes, "Chica gosta é de Mulher", a história narrada é de uma menina que descobre que gosta de mulher e sofre perseguição e agressão por parte das pessoas da "cidadezinha" onde mora, entretanto, não se intimida e luta para provar a todos que sua preferência deve ser respeitada, pois acredita no amor:

Naquela sociedade

Era homem com mulher

Sem nenhuma novidade

Sem melzinho na colher

Escolher felicidade

Nem se muito se quiser 
O povo já se juntava

Prum ataque planejar

De raiva se espumava

A gritar e a xingar

Só faltava balaclava

Pra merda consolidar

Foram juntos caminhando

Para Chica encurralar

Com o ódio fervilhando

Pra bater e pra matar

Quando a casa foi chegando

Se puseram a atacar

Era tanta da corrente

Tinha até tocha de fogo

Uma multidão furente

Que não aceitava o novo

Mas a Chica imponente

Saiu pra falar cum povo

A massa ficou surpresa

Com a tamanha valentia

Assustada com a brabeza

Nem um pio mais se ouvia

Chica cheia de certeza

Falou tudo o que queria

Ela não se importava

Se gritavam "sapatão!"

Ela muito acreditava

Na grande revolução

Que só o amor causava

Preenchendo o coração [...] (ARRAES, 2017, s/p, grifos nossos).

No conto "Os olhos Verdes de Esmeralda", também uma história de relacionamento entre duas mulheres, a personagem Esmeralda se apaixona por Marina, ao se conhecerem em uma festa de confraternização dos calouros no campus da universidade. A partir de então, passam a morar juntas para dividir despesas e o amor entre ambas cresce. No entanto, as famílias nunca desconfiaram de nada. Ao terminarem a universidade, retornam, cada qual, para a casa de seus pais. Assim o fazem para evitarem constrangimentos. Ambas já estão empregadas e quando tem saudades, viajam para se encontrarem. Certa feita, estavam em uma 
festinha familiar quando, movidas pelo desejo uma da outra, decidem ir embora. No caminho, Esmeralda para no farol e elas se beijam apaixonadamente. Ao engatar o carro, com as emoções à flor da pele, Esmeralda "faz cantar os pneus no asfalto molhado" quando a viatura sinaliza para pararem. Nesse momento ambas são surpreendidas por uma situação de racismo, violência e estupro.

Perdida em pensamentos, engatou, desajeitada, a primeira e fez cantar os pneus no asfalto molhado. Viu-se seguida por uma viatura policial, sinalizando para que encostasse e parasse. Pensou: “Droga, logo hoje!”. Parou. Distração ou instinto, segurou a mão de Marina, acariciando-lhe a perna com carinho protetor. O sargento percebeu o gesto ao cercar-se do carro. Ela recolheu rapidamente a mão, retraindo-se. "Temos dois machos aqui. Hei este aqui está com lentes de contato verdes. Metida a americana, 18 Hein?", falou, apertando rudemente o rosto de Esmeralda entre o indicativo e o polegar. O sargento branco, alto, gordo, cara de bolacha metida na banha, sorriu maliciosamente e, com maldade e despeito, perguntava-se: "Por que ele não conseguia pegar uma mulher? Estas duas sapatas filhas da puta ali na sua frente. Não eram feias, apesar de negras". Ele odiava sapatas, estavam sempre com uma gostosa ao lado. Odiava negros também, principalmente os famosos. Estavam sempre acompanhados por loiras de fechar sinal e mais umas tantas correndo atrás [...] Retirou-a do carro, colocou-a no camburão e, ali mesmo, passou a violentá-la. "Não gosta de homem, não é? Vou fazer você gostar! Nunca conheceu um, não é...? Você vai sentir o que é bom!" Gritava ele brutalmente. Espancou-a, desfechando golpes no rosto, na altura dos olhos [...] Esmeralda, boca tampada pelas mãos gordas e sebosas do policial. A língua viscosa com cheiro e gosto de cigarros, conhaque barato e maconha lambia-lhe os olhos verdes como querendo sugá-los. (ALVES, 2011, p.65, grifos nossos).

Em "Cinco Cartas para Rael”, a personagem narradora é uma secretária negra que escreve cinco cartas endereçadas a seu ex namorado, desabafando, dentre outras coisas, sobre seu sentimento de rejeição por ter sido trocada por uma mulher branca. Em dado momento, a personagem revela o assédio de seu chefe branco e sua vontade de sair do emprego para se tornar fotógrafa, trabalho realizado nas horas vagas e que traz muito prazer a ela:

Eu quero ser fotógrafa artística, revelar o mundo segundo minha lente objetiva. Tenho, talvez, por muito tempo, que ouvir os desaforos daquele barrigudo do meu chefe. Nojento, acha que mulher, principalmente mulher negra, está à disposição dos seus arroubos lascivos. Já aprontou boas. É desrespeito em cima de desrespeito. Só falta cantar: "Aí, meu Deus, que bom seria se voltasse a escravidão/eu 


\begin{abstract}
pegava esta mulata e prendia...”. Convenhamos, seria o coroamento do desacato. Tentou agarrar-me à força. Vou fingindo que não vejo. Desvencilhando-me da melhor maneira. Qualquer dia, encho de tapas aquela cara branca, gordurenta, macerada pelo tempo, de barbeado mal feito. Perco o emprego. Ele se acha o dono do mundo. Acredite, ainda não lhe meti a mão na cara” (ALVES, 2011, p.71, grifos nossos)
\end{abstract}

Diante das questões abordadas acima pelas autoras, entendemos que a violência contra a mulher negra, em decorrência do racismo, é pontuada de forma clara e objetiva, mas não com o intuito de vitimizar a mulher negra, mas contrariamente, mostrar sua força, mesmo diante das barbáries cometidas pelo paternalismo branco. As personagens se saem bem, apesar de tudo o que passam. Talvez essa força vem da não fragilidade histórica pontuada por Sueli Carneiro anteriormente, desde o período da escravidão, já que elas vêm 19 resistindo às intempéries do machismo e racismo institucionalizados. Isso mostra uma tentativa de trazer para a ficção o que acontece na realidade. Mulheres negras que apanham da vida, mas aprendem a dar a volta por cima e a persistir na luta contra a dominação masculina patriarcal branca. Embora não haja indícios de que o cordel "Chica Gosta é de Mulher" trata de uma personagem negra, inferimos que sim, devido ao projeto literário da autora em trazer para seus cordéis e poemas, as vidas das mulheres negras.

Djamila Ribeiro discorrendo sobre o racismo, define:

Racismo tem a ver com poder, com privilégios. A população negra não tem poder historicamente. Racismo é uma problemática branca, portanto temos que começar pela desmistificação. Dentro de comunidades marginalizadas pode haver preconceito, isso é uma coisa, mas poder é a definição de racismo (RIBEIRO, 2018, p. 111,112).

Nesse sentido, vemos claramente o racismo nos excertos acima, nos dois contos de Alves. A hegemonia e os privilégios sociais concedidos ao homem branco, o "habilita" a agir de forma empoderada com relação à mulher. Esse homem se vê em uma situação de poder diante de um ser considerado sua "posse". Essa vulnerabilidade da mulher negra vem de seu passado escravocrata quando havia uma ação de violência contra a mulher negra cujo corpo servia de objeto de uso e abuso pelo senhor fazendeiro. 
Angela Davis, ao tratar do estupro, afirma que durante a escravidão, as mulheres, além de serem açoitadas, eram ainda estupradas. Segundo a teórica:

O estupro, na verdade, era uma expressão ostensiva do domínio econômico do proprietário e do controle do feitor sobre as mulheres negras na condição de trabalhadoras. Os abusos especialmente infligidos a elas facilitavam a cruel exploração econômica de seu trabalho (DAVIS, 2016, p. 20).

É nesse sentido que a mulher negra se torna alvo de maiores abusos e discriminações nas sociedades ocidentais nas quais não há uma política de controle dessas violências sofridas pelas mulheres, especialmente por questões de raça e classe. Davis (2016) ainda comenta que o abuso sexual sofrido pelas mulheres negras por seus abusadores brancos nem sempre mostram uma violência aberta e pública. Esses homens, "convencidos de que seus atos são naturais", aponta para um drama diário das mulheres negras. Para Davis, elas são tratadas como promíscuas e imorais por políticos, intelectuais, literatos e, com isso, esse estereótipo acaba por ser validado. São por essas e outras questões que o feminismo negro 20 surgiu: para lutar por essas mulheres batalhadoras e sofridas, ao longo de séculos, nas mãos da hegemonia ocidental branca e patriarcal.

\section{Considerações Finais}

A literatura de cordel, apesar de representar resistência, pois sobreviveu à margem por muito tempo, sendo julgada como nãoliteratura, infelizmente representa também esse território no qual predomina a supremacia masculina. Prova disso é a composição atual da Academia Brasileira de Literatura de Cordel, que, dos quarenta membros, apenas cinco são mulheres. No entanto, a resistência das mulheres em se fazerem aceitas nesse meio reforça, de certa forma, a característica forte do cordel de continuar se reinventando e buscando ser instrumento de popularização das diversas vozes que querem se manifestar em versos.

Atualmente é possível encontrar mais de setenta mulheres no rol de cordelistas femininas já consagradas. E elas são arretadas! Participam das feiras e dos encontros, mesmo diante das caras feias dos homens, que não querem ceder espaço aos seus versos, como afirma a cordelista indígena Auritha Tabajara, no documentário "As cordelistas”, exibido na 
TV Brasil em setembro de 2019. Jarid Arraes, nesse mesmo documentário, afirma que há um machismo muito forte nos eventos, e que muitas vezes as mulheres cordelistas não são convidadas e nem tampouco bem-vindas neles. Mesmo assim, elas não se calam. A própria Arraes, como vimos nos seus três cordéis selecionados acima, trata de forma nua e crua o racismo e a violência perpetuados por uma sociedade hipócrita e rude.

O blog "Cordel de saia", criado pela cordelista Dalinha Catunda, reúne diversos trabalhos de mulheres cordelistas, em um espaço virtual que dá voz às mulheres que querem conhecer mais sobre o cordel ou mesmo publicar seus versos, pois queiram ou não, as mulheres estão cada vez mais empoderadas e buscando união em nome da causa feminista, ou em nome da justiça social.

Esse empoderamento das cordelistas vale também para escritoras mulheres nos gêneros literários diversos, como contos, romances, poesia, crônicas. $\mathrm{O}$ espaço para a mulher negra em todas as formas de arte ainda é mais precário do que para a mulher branca. No entanto, a mulher negra está cada vez mais vencendo os desafios de sua história de opressão escravagista que perdura até os dias de hoje, sob outra roupagem, haja vista o tanto de mulheres negras que ainda estão em subempregos como domésticas, auxiliares de limpeza, prostitutas, etc. Além disso, como apontado nos contos mencionados nesse artigo, temos as 21 mulheres negras relacionadas à questões de gênero, no caso das lésbicas negras, que tendem a sofrer dupla discriminação, a negra secretária que é trocada por uma branca pelo seu parceiro negro apenas porque ele precisa de reconhecimento social por parte de seus párias e ainda é assediada por seu chefe e a sofredora personagem que expõe suas dores desde a infância por ter vivenciado cenas de racismo ao longo de sua vida, chegando na fase adulta com pensamentos suicidas.

Isso exposto, finalizamos com pensamentos de que as mulheres negras não se calem e não desistam nunca de ocupar os espaços de seu merecimento e direito e que as mulheres brancas tomem consciência e busquem conhecimento (algumas já estão nesse caminho) das diferenças entre as questões e prioridades de pauta do feminismo branco e negro para que possam, assim, corroborar a luta as companheiras negras. 


\section{Referências}

ALVES, Miriam. Mulher Mat(r)iz. Belo Horizonte: Nandyala, 2011.

ARRAES, Jarid. Chica gosta é de mulher. Disponível em: http://jaridarraes.com/cordelchica-gosta-e-de-mulher/.

ARRAES, Jarid. Corpo escuro. [Folheto de cordel] / Jarid Arraes.

ARRAES, Jarid. Quem tem crespo é rainha. [Folheto de cordel] / Jarid Arraes.

AS CORDELISTAS. Caminhos da reportagem. TV Brasil. 2019. (26'59"). Disponível em: <https://www.youtube.com/watch?v=8tz7xPFjH2c > Acesso em 14/01/2020.

BARROS, Miguel Pereira. Relações de gênero na literatura de cordel. Curitiba: Appris, 2015.

CARNEIRO, Sueli. Enegrecer o feminismo: a situação da mulher negra na América Latina a partir de uma perspectiva de gênero. In: HOLLANDA, Heloísa Buarque de (org.). Pensamento feminista: conceitos fundamentais. Rio de Janeiro: Bazar do Tempo, 2019.

COLLINS, Patrícia Hill. Pensamento feminista negro: conhecimento, consciência e a política do empoderamento. São Paulo: Boitempo, 2019.

COLLINS, Patrícia Hill. Pensamento feminista negro: o poder da autodefinição. In: HOLLANDA, Heloísa Buarque de (org.). Pensamento feminista: conceitos fundamentais. Rio de Janeiro: Bazar do Tempo, 2019.

DAVIS, Angela. Mulheres, Raça e Classe. Tradução de Heci Regina Candiani, 1 ed, São Paulo: Boitempo, 2016.

DUARTE, Constância Lima. Feminismo: uma história a ser contada. In: HOLLANDA, Heloísa Buarque de (org.). Pensamento feminista brasileiro: formação e contexto. Rio de Janeiro: Bazar do Tempo, 2019.

FANON, Frantz. Pele negra, máscaras brancas. Salvador: EDUFBA, 2008. 
RIBEIRO, Djamila. Quem tem Medo do Feminismo Negro?, 1 ed, São Paulo: Companhia

das Letras, 2018.

MOREIRA, Núbia. Movimento feminista negro no Brasil. 2016. (47m32s). Disponível em: <https://www.youtube.com/watch?v=T QaoLa1YlFw\&t=1816s $>$. Acesso em: $08 \mathrm{dez} .2020$.

RIBEIRO, Djamila. Feminismo negro: para além de um discurso identitário. Revista Cult, 2017. Disponível em: $<$ https://revistacult.uol.com.br/home/feminismo-negro-para-alemdeum-discurso-identitario/>. Acesso em: 08 dez. 2020.

PNAD CONTÍNUA (PESQUISA NACIONAL POR AMOSTRA DE DOMICÍLIOS CONTÍNUA). Quantidade de homens e mulheres. 2019. Disponível em: <https://educa.ibge.gov.br/jovens/conheca-obrasil/populacao/18320-quantidade-dehomens-e-mulheres.html $>$. Acesso em: 08 dez. 2020. 


\section{THE BLACK FEMINISM IN JARID ARRAES' 'CORDEL' LITERATURE AND IN MIRIAM ALVES' SHORT STORIES}

RESUMEN/ABSTRACT: This article aims to reflect upon black feminism in Brazil, bringing some theoretical voices which trace a route for this movement. For such, two women writers will keep up with those voices. We will check how Jarid Arraes libertarian tune echoes in her verses as well as on how perspective Miriam Alves' harsh narrative show ways to different views on racism, violence and sexism. This way, Arraes verses as much as Alves prose are a "spit on the face" of the prejudices and stereotypes created against black women.

Palabras Clave/KeYwords: Black Feminism. "Cordel” Literature. Jarid Arraes. Prose. Miriam Alves.

\section{Flávia Andrea Rodrigues BENFATTI}

Professora Adjunta do Instituto de Letras e Linguística da Universidade Federal de Uberlândia (ILEEL - UFU); Docente do Programa de Pós-Graduação em Estudos Literários (PPLET). Pós-Doutoranda da Universidade Estadual Paulista (UNESP) campus de São José do Rio Preto - SP.

Universidade Federal de Uberlândia E-mail: flaviarbenfatti@gmail.com

Gláucia Mendes da SILVA

Professora Adjunta do Instituto de Letras e Linguística da Universidade Doutoranda em Teoria Literária no Programa de Pós Graduação em Estudos Literários do Instituto de Letras e Linguística da Universidade Federal de Uberlândia (ILEEL - UFU)

Universidade Federal de Uberlândia E-mail: flaviarbenfatti@gmail.com

Recebido em: 23/04/2020

Aprovado em: 28/o1/2021 